\title{
PEMANFAATAN CITRA PENGIDERAAN JAUH PADA GOOGLE EARTH UNTUK PEMBUATAN PETA CITRA DI KECAMATAN MARGA, KABUPATEN TABANAN
}

\author{
I Wayan Krisna Eka Putra \\ Masuk: 01042017 / Diterima: 10042017 / Dipublikasi: 30062017 \\ () 2017 Fakultas Hukum dan IImu Sosial UNDIKSHA dan IG
}

\begin{abstract}
Marga sub-district is one of the sub-districts where most of its villages do not have village map especially image map. The purpose of this activity is to (1) form the knowledge and skills of village officials in terms of creating image maps, and (2) facilitating village officials in order to produce image maps. Stages of implementation of the activities are: (1) preparation which includes the preparation of materials and guidelines to download remote sensing image data, and to create image maps, and validation of image data as basic data, (2) implementation which includes providing technical guidance on how to download remote sensing imagery data, (3) evaluating the success of the activity of creating image maps from remote sensing imagery data, and map printout process. This activity runs smoothly according to plan, only the participants still cannot independently create a map, especially when doing the process of map layout.
\end{abstract}

Key words: Remote Sensing, Google Earth, Image Map

\begin{abstract}
Abstrak Kecamatan Marga merupakan salah satu kecamatan yang sebagian besar desa-desa nya belum memiliki peta desa khususnya peta citra. Tujuan dari kegiatan ini adalah agar (1) terbentuknya pengetahuan dan keterampilan aparat desa dalam hal membuat peta citra, dan (2) memfasilitasi aparat desa agar dapat menghasilkan peta citra. Tahapan pelaksanaan kegiatan yaitu: (1) persiapan yang meliputi penyusunan materi dan pedoman untuk download data citra penginderaan jauh pada Google Earth menggunakan software StichMaps dan Quantum GIS, penyusunan materi dan pedoman untuk membuat peta citra, serta validasi data citra yang akan digunakan sebagai data dasar, (2) pelaksanaan yang meliputi pemberian bimbingan teknis cara download data citra penginderaan jauh pada Google Earth, (3) evaluasi keberhasilan kegiatan membuat peta citra dari data citra penginderaan jauh pada Google Earth, dan proses print out peta. Kegiatan ini berjalan dengan lancar sesuai rencana, hanya saja peserta masih belum bisa mandiri membuat peta terutama pada saat melakukan proses layout peta.
\end{abstract}

Kata-Kata kunci : Penginderaan Jauh, Google Earth, Peta Citra

\section{Pendahuluan}

Tersedianya peta citra pada masing-masing kantor desa akan

I Wayan Krisna Eka Putra

Jurusan Survei dan Pemetaan, FHIS UNDIKSHA Singaraja

krisna.ekaputra@yahoo.com lebih memudahkan aparat desa untuk mengenali wilayahnya masingmasing. Belum tersedianya peta citra pada setiap desa mengindikasikan perlunya dilakukan sosialisasi dan pelatihan penggunaan teknologi untuk 
membuat peta citra melalui program pengabdian masyarakat. Harapannya aparat desa bisa membuat sendiri peta citra tanpa harus mengeluarkan biaya yang cukup mahal.

Berdasarkan fakta empirik yang ditemukan pada saat observasi awal menunjukkan bahwa hampir semua desa-desa yang ada di Kecamatan Marga belum memiliki peta desa, khususnya peta citra. Hal ini terlihat dari peta yang digunakan masih berupa peta garis yang dibuat secara manual tanpa memperhatikan kaidah kartografi dalam pembuatan peta.

Berdasarkan informasi dari salah satu Kepala Desa (Kepala Desa Tua) yang berhasil dimintai informasi, bahwa keadaan tersebut dikarenakan sumber daya manusia (SDM) aparat desa belum bisa membuat peta. Apabila menggunakan tenaga luar untuk membuatkan peta, tentunya akan berimplikasi pada biaya yang jumlahnya tidak sedikit. Aparat desa juga belum memandang penting manfaat peta yang saat ini hanya digunakan sebagai pajangan di dinding kantor desa.

Alasan biaya serta SDM aparat desa yang belum bisa membuat peta bukan merupakan alasan yang rasional mengapa setiap desa belum memiliki peta, jika saja aparat desa mengetahui dan bisa memanfaatkan perkembangan teknologi saat ini. Kecamatan Marga merupakan kecamatan yang mempunyai sifat kekotaan, dimana hampir sebagian besar kantor desa sudah dilengkapi jaringan internet.
Padahal jika dilengkapi dengan jaringan internet, instalasi program Google Earth, StichMaps, dan Quantum GIS pada komputer di masing-masing kantor desa, sudah memenuhi syarat untuk membuat peta citra. Hanya saja SDM yang mengoperasikannya harus diberikan pelatihan terlebih dahulu.

Berdasarkan permasalahan tersebut, maka kegiatan pengabdian kepada masyarakat ini merupakan hal yang penting dilakukan untuk memberikan pengetahuan kepada aparat desa mengenai pemanfaatan citra penginderaan jauh pada google earth untuk membuat peta citra. Dengan demikian harapannya, aparat desa bisa membuat sendiri peta citra wilayahnya masing-masing dengan memanfaatkan data gratis (Google Earth) serta software open source (tanpa lilensi).

\section{Metode}

Metode yang digunakan dalam kegiatan ini adalah dalam bentuk pelatihan. Secara umum tahapan kegiatan pelatihan ini terdiri dari tiga tahapan utama yaitu :

Tahap persiapan

Tahap persiapan merupakan tahap membuat materi pelatihan dan validasi citra. Materi yang akan dibuat dalam kegiatan ini meliputi: (1) cara menggunakan Google Earth, (2) cara melakukan download data, dan (3) cara membuat peta citra. Untuk proses validasi dilakukan melalui komparasi perubahan kenampakan 1 tahun terakhir di lapangan terhadap kenampakan yang ada pada citra. 
Tahap pelaksanaan

Tahap pelaksanaan merupakan tahap pemberian bimbingan teknis dan dilanjutkan dengan evaluasi keberhasilan program. Bimbingan teknis yang diberikan selama kegiatan meliputi : (a) bimbingan teknis cara menggunakan Google Earth, (b) bimbingan teknis melakukan download data, dan (c) bimbingan teknis membuat peta citra. Proses evaluasi menggunakan indikator ketercapaian kegiatan yang meliputi: menggunakan Google Earth, download data, serta proses membuat peta.

Tahap proses pirnt out peta

Proses print out peta citra merupakan tahapan akhir agar peta yang sudah dibuat bisa ditampilkan pada kertas.

Ketiga tahapan tersebut divisualisasikan melalui diagram alir pelaksanaan kegiatan pelatihan sebagai berikut.

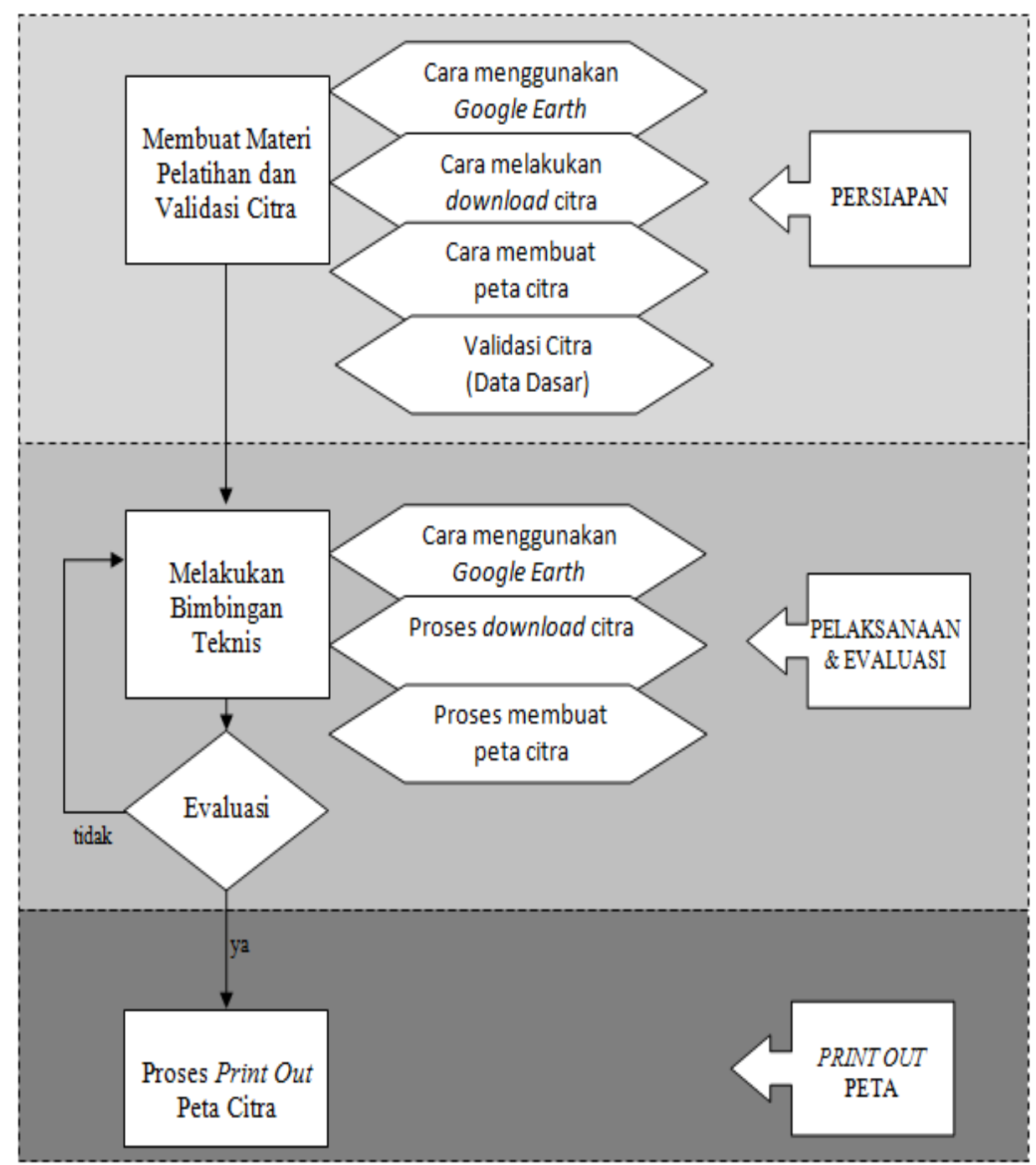

Gambar 1. Diagram Alir Pelaksanaan Kegiatan Pelatihan 


\section{Hasil dan Pembahasan Hasil Tahap Persiapan}

Tahap persiapan difokuskan pada kegiatan penyusunan materi pelatihan yang akan digunakan pada saat pemberian bimbingan teknis. Isi dari materi pelatihan yang dihasilkan terdiri dari 4 bagian utama yang meliputi : (a) pengantar pembuatan peta desa/kelurahan, (b) cara menjalankan aplikasi Google Earth, (c) cara melakukan download citra, dan (d) cara membuat peta citra pada QuantumGIS. Pada tahap persiapan juga dilakukan pendataan ke Kecamatan Marga, Kabupaten Tabanan untuk mendata peserta yang akan dijadikan sebagai subjek dalam pelaksanaan pelatihan. Hasil yang diperoleh, Camat Marga mengapresiasi kegiatan pelatihan yang dilaksanakan serta menunjuk 3 Desa yang dijadikan subjek dalam pelatihan tersebut yaitu Desa Petiga, Desa Tua, dan Desa Baru.

Selanjutnya setelah ditetapkan subjek pelaksanaan, dilakukan kegiatan validasi data terlebih dahulu untuk memastikan data citra Penginderaan Jauh pada Google Earth update sesuai perubahan di lapangan.

Teknisnya Tim menanyakan kepada aparat desa terkait perubahan fisik kenampakan 1 Tahun terakhir, kemudian mengambil posisinya dan mengkomparasikan dengan kenampakan yang terekam pada citra Penginderaan Jauh pada Google Earth. Hal ini ditujukan untuk memastikan bahwa data yang terekam pada Google Earth merupakan kenampakan yang terupdate. Hasil validasi yang diperoleh disajikan pada Gambar 1.
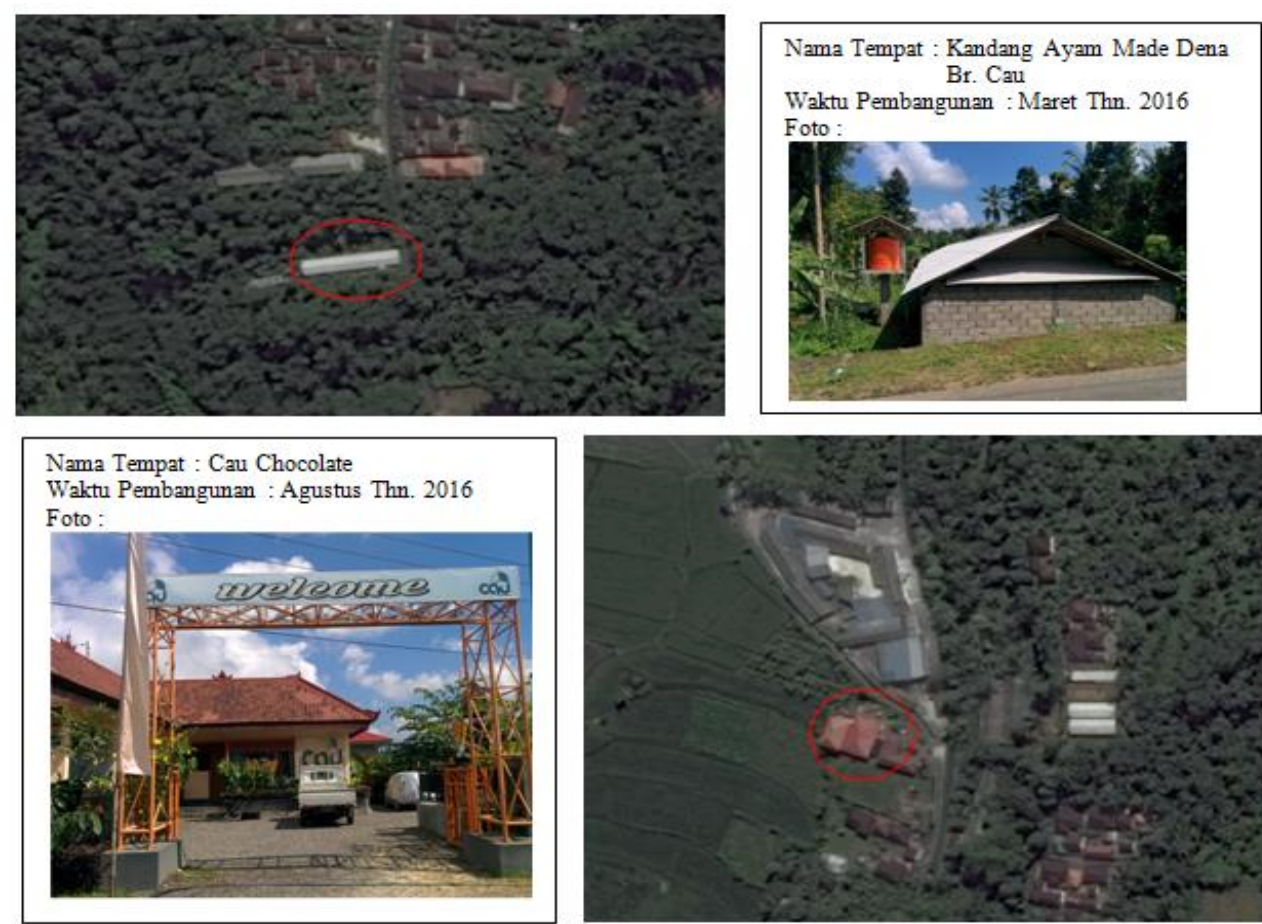

Gambar 1. Hasi Validasi Citra Penginderaan Jauh Pada Google Earth 
Memperhatikan hasil validasi citra, membuktikan bahwa citra Penginderaan Jauh pada Google Earth sudah menunjukkan kenampakan wilayah 1 tahun terakhir, bahkan kenampakan objek yang mengalami perubahan Bulan Maret tahun 2016 pun sudah terekam pada citra. Dengan demikian sudah bisa dipastikan, data tersebut dapat digunakan sebagai data dasar untuk membuat Peta
Citra di masing-masing desa yang menjadi subjek pelaksanaan.

\section{Hasil Tahap Pelaksanaan}

Tahap pelaksanaan berupa bimbingan teknis cara membuat peta meliputi kegiatan outdoor (lapangan) dan indoor (ruangan). Kegiatan di lapangan seperti pada Gambar 2 dilakukan secara partisipatif bersama aparat Desa dan mahasiswa sebagai tenaga lapangan.
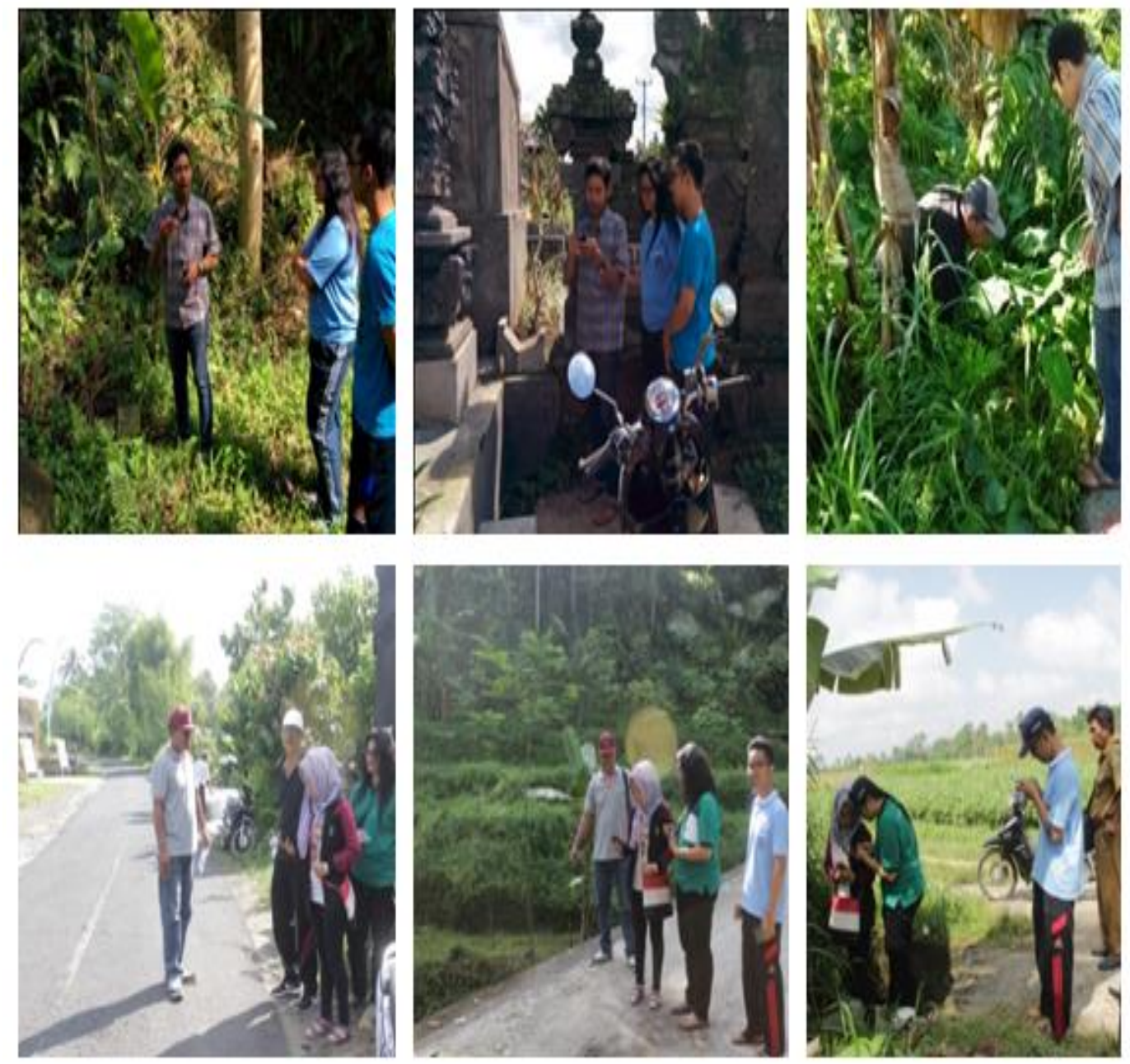

Gambar 2. Dokumentasi Kegiatan Akuisisi Data Koordinat Batas Desa 


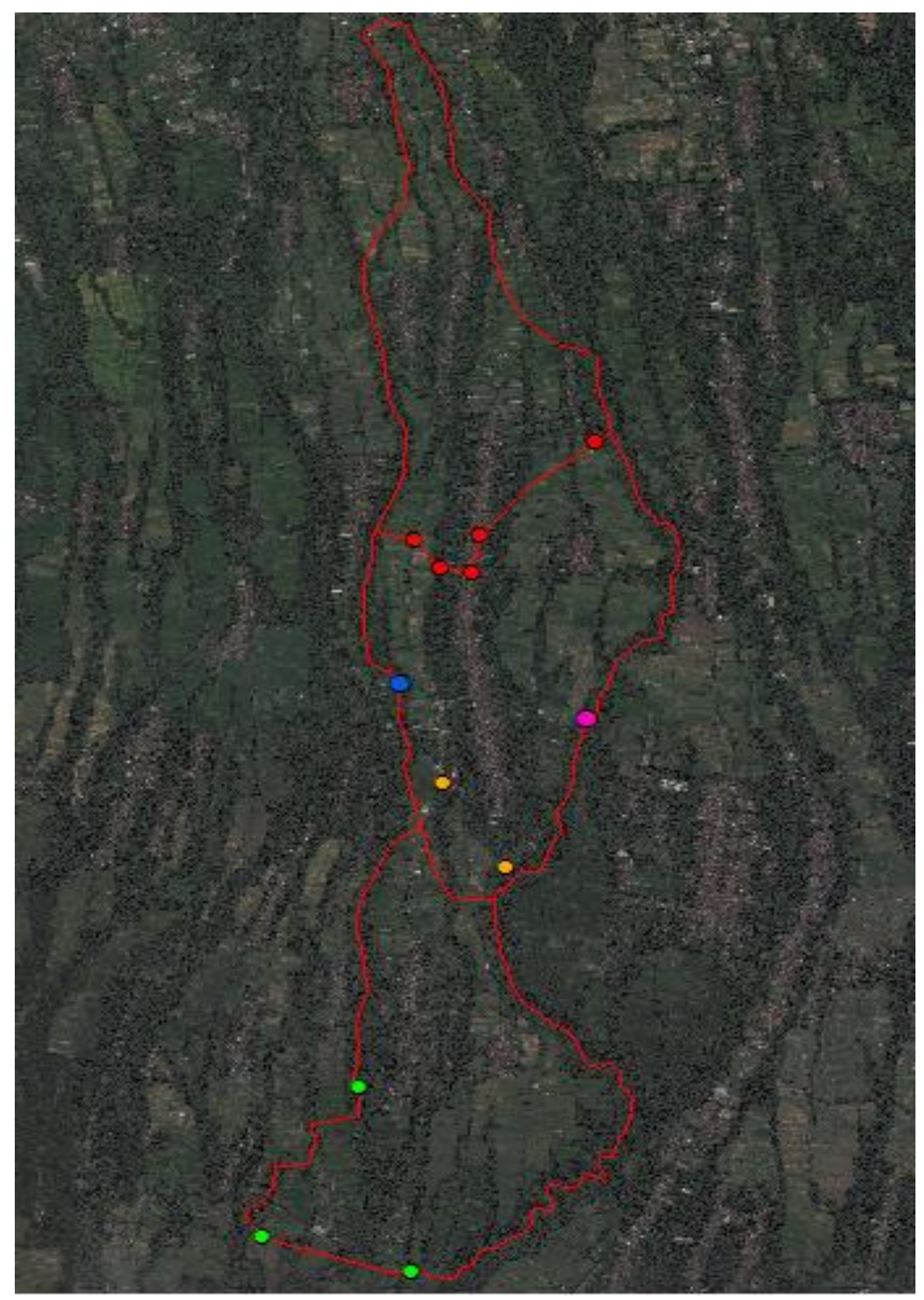

Gambar 3. Hasil Plotting Koordinat Batas Desa

Kegiatan di lapangan ini ditujukan untuk melakukan akuisisi koordinat batas wilayah masing-masing desa. Aparat desa bertugas menunjukkan lokasi batas desa, sementara Tim Pelaksana bersama mahasiswa melakukan akuisisi koordinat batas wilayah menggunakan Global Positioning System (GPS). Setelah proses akuisisi koordinat batas desa, dilanjutkan dengan plotting data sehingga hasil yang diperoleh seperti pada Gambar 3.

Selanjutnya kegiatan bimbingan teknis yang bertempat di Ruang Pertemuan Kantor Desa Tua diawali dengan penyampaian materi konsep dasar pemetaan (Gambar 4). 

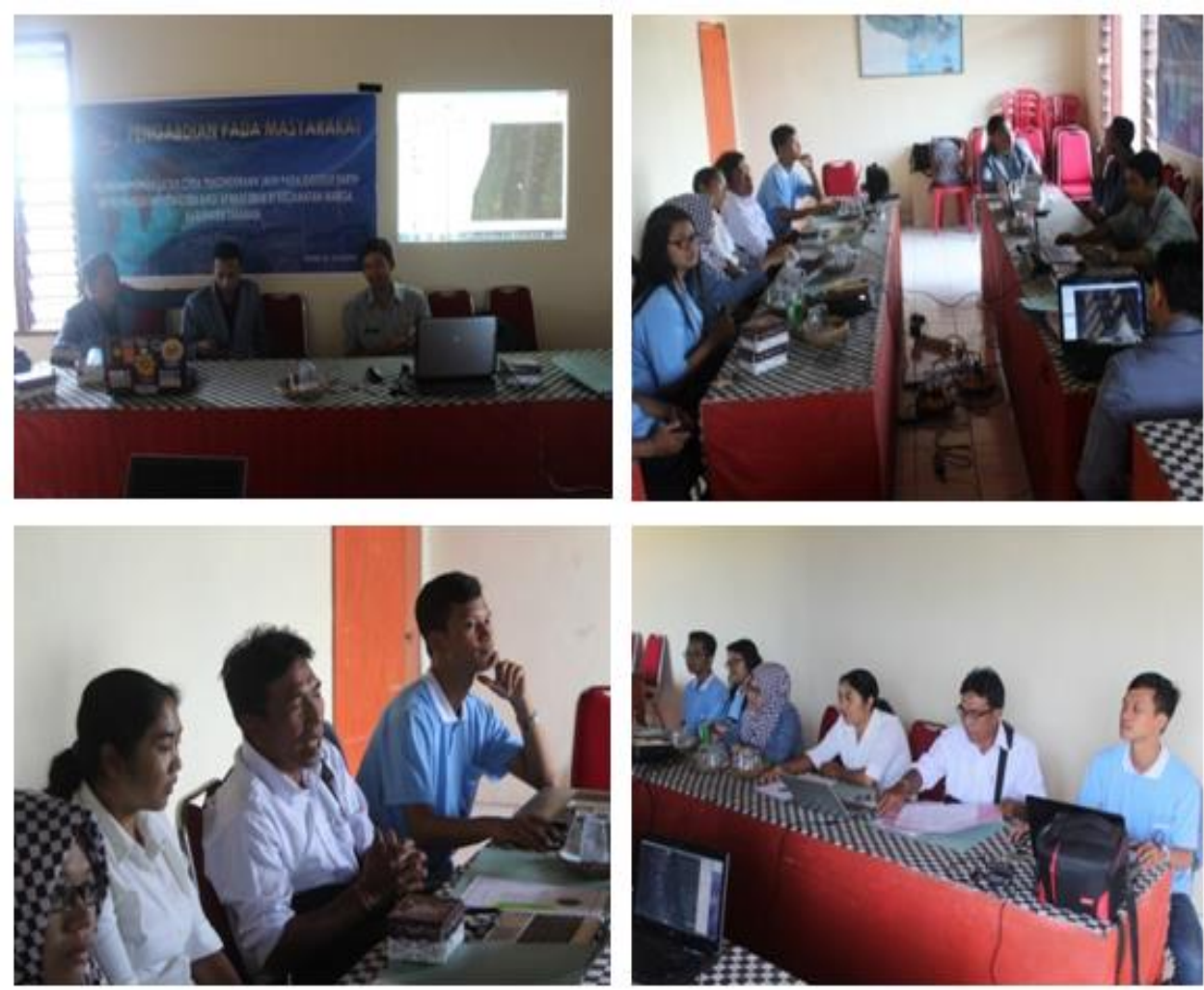

Gambar 4. Dokumentasi Kegiatan Bimbingan Teknis Cara Membuat Peta

Melalui bimbingan teknis
cara membuat peta, peserta
dibimbing untuk menjalankan
aplikasi Google Earth, download
data serta layout peta.

Pada saat pemberian bimbingan teknis, hampir semua peserta masih kebingungan mengikuti panduan yang ada baik pada handout materi maupun yang disajikan pada slide. Hal ini disadari karena peserta masih sangat awam dengan kegiatan yang dilaksanakan. Sesuai hasil evaluasi yang diperoleh, peserta masih kurang paham cara membuat peta khususnya proses layout peta. Hal ini terbukti dari hasil evaluasi, skor pada tahap layout masih rendah. Masih rendahnya keterampilan peserta dalam membuat peta merupakan suatu kewajaran, mengingat background peserta yang bervariasi. $\mathrm{Di}$ samping itu juga peserta baru kali pertama mendapatkan pelatihan untuk membuat peta. Dengan demikian proses pembuatan peta khususnya layout peta dibantu oleh tim pelaksana. Tujuannya agar peta yang dihasilkan sesuai dengan kaidah kartografi. Selanjutnya kegiatan pelatihan dan pendampingan dapat dilakukan secara berkelanjutan untuk meningkatkan keterampilan masyarakat dalam mengoperasikan komputer dan aplikasi pemetaan guna menghasilkan peta administrasi desa. 


\section{Hasil Tahap Print Out Peta}

Tahap print out peta merupakan tahapan akhir dari kegiatan pengabdian pada masyarakat ini. Sebelum proses print out peta, terlebih dahulu dilakukan layout peta yang difasilitasi oleh tim pelaksana. Walaupun demikian persetujuan dari pihak aparat desa tetap digunakan mengingat yang lebih mengetahui wilayah desanya adalah aparat desa masing-masing. Untuk itu sebelum proses print out, terlebih dilakukan konfirmasi peta yang sudah di-layout kepada masing-masing aparat desa.
Tujuannya adalah untuk memastikan bahwa apa yang tersaji dalam peta sudah sesuai dengan kondisi di lapangan.

Pada dasarnya aparat desa sudah menyetujui peta yang dihasilkan untuk di-print out. (peta yang sudah siap di print out disajikan melalui Gambar 5, 6 dan 7). Hanya saja menurut Kepala Desa batas desa yang digunakan tersebut masih belum definitif mengingat masih belum dilakukannya pemetaan batas desa secara partisipatif pasca pemekaran desa.

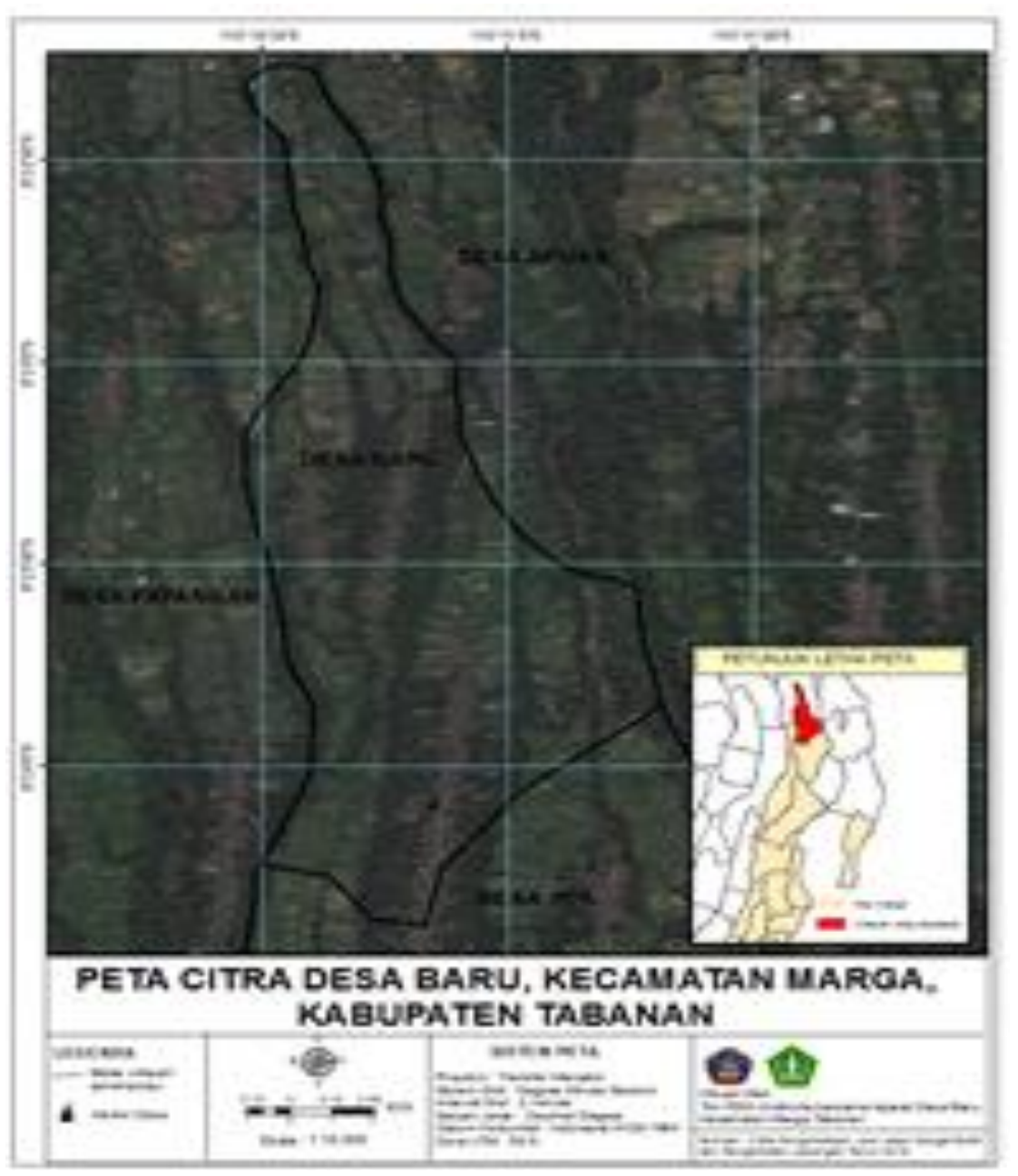

Gambar 5. Peta Citra Desa Baru 


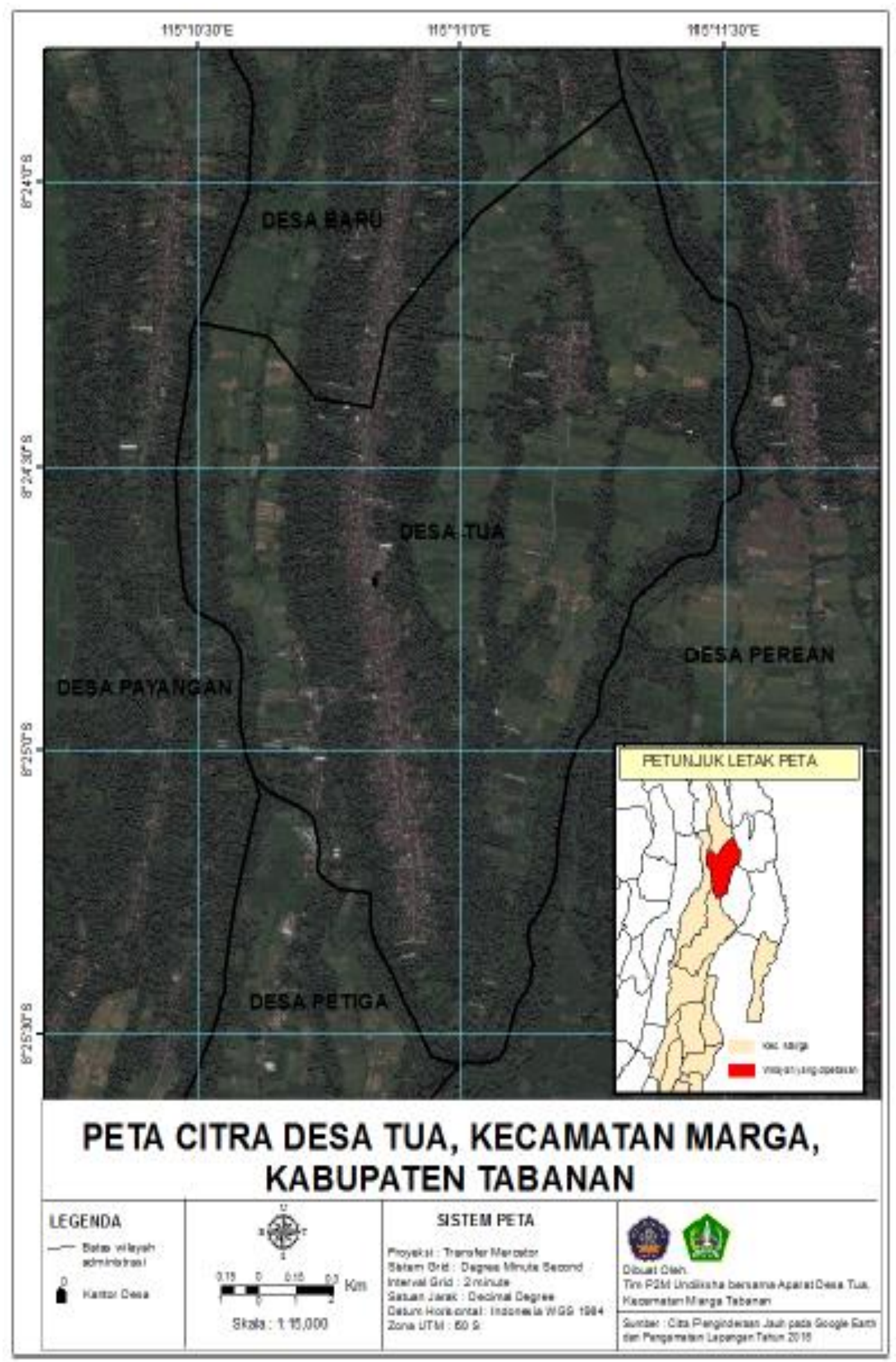

Gambar 6. Peta Citra Desa Tua 


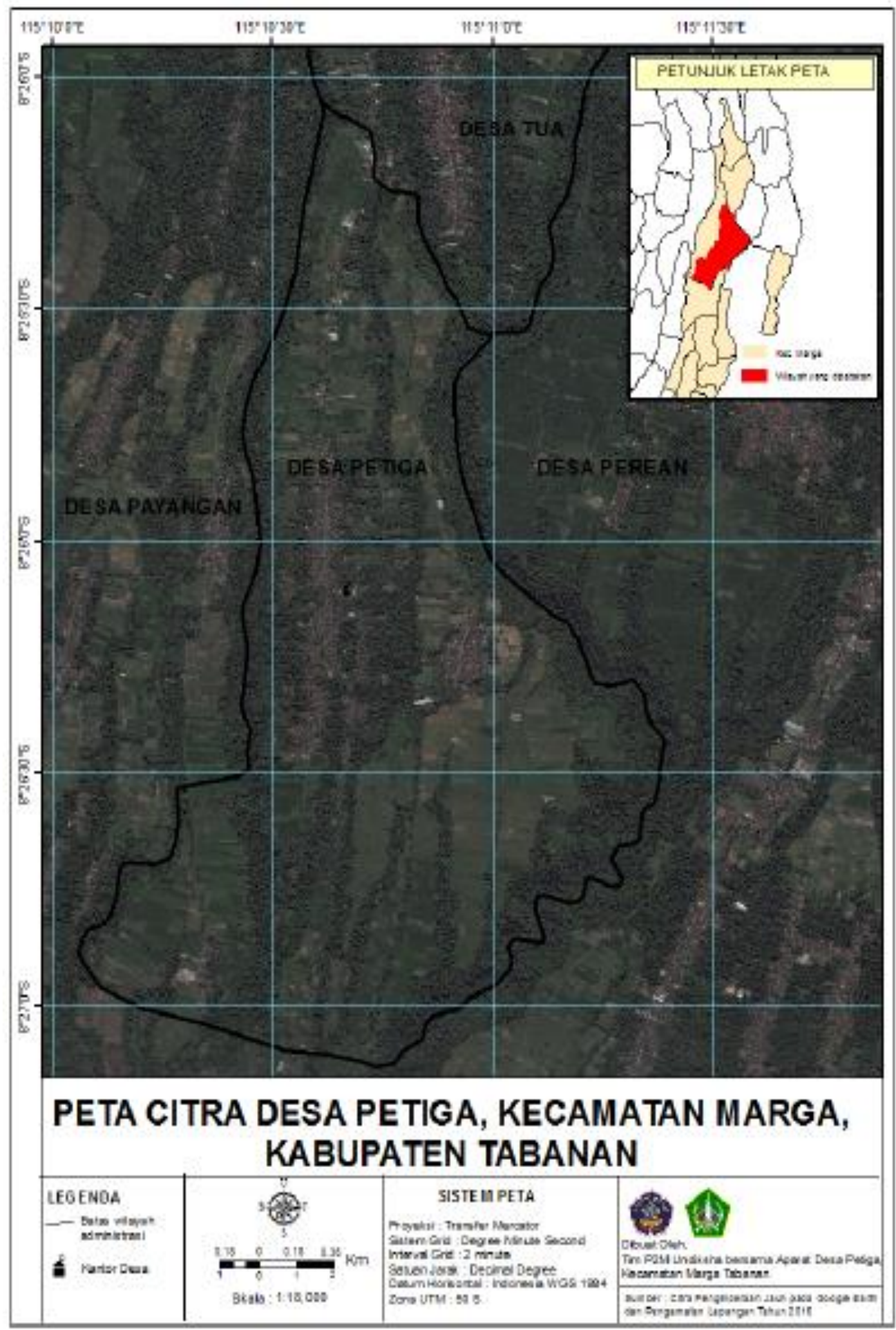

Gambar 7. Peta Citra Desa Petiga 


\section{Penutup}

\section{Simpulan}

Berdasarkan kegiatan yang sudah dilaksanakan, maka dapat disimpulkan sebagai berikut.

- Kegiatan pelatihan pembuatan peta pada tiga desa (Desa Petiga, Tua dan Baru) di Kecamatan Marga, Kabupaten Tabanan berjalan sesuai rencana, hanya saja keberhasilan program pelatihan ini masih belum bisa maksimal terutama keterampilan peserta dalam melakukan proses layout peta.

- Peta yang dimiliki masing-masing desa belum valid terutama batas desa, sehingga kegiatan update peta wilayah merupakan kegiatan yang urgen untuk dilaksanakan.

\section{Saran}

Saran yang dapat diberikan merujuk pada kegiatan yang sudah dilaksanakan yaitu :

- Perlu dilakukan kegiatan pelatihan yang lebih intensif dalam waktu yang lebih lama, sehingga keterampilan aparat desa dalam membuat peta bisa ditingkatkan demi mendukung terealisasinya program one map policy.

- Pemerintah Desa perlu melakukan koordinasi dengan Camat atau Bupati terkait dengan batas desa yang belum definitif untuk melakukan pemetaan partisipatif agar peta desa yang digunakan valid dan mendapat persetujuan kedua pihak desa yang berbatasan.

\section{Daftar Pustaka}

Arita, Dewi dan Andri Pranolo. 2014. Pemanfaatan Aplikasi Google Earth Sebagai Media Pembelajaran Gografis Menggunakan Metode Image Enhancement. Makalah dalam rangka Simposium Nasional RAPI XIII-2014 FT UMS.

Departemen Dalam Negeri RI. 2007. UU No. 4 Tahun 2011 Tentang Informasi Geospasial.

Isnandar, Nandang. 2008. Kajian Akurasi Pemanfaatan Citra Quickbird Pada Google Earth Untuk Pemetaan Bidang Tanah. Tesis. Bandung : Institut Teknologi Bandung.

Rosdiana, P. dan Shinta. 2011. Peningkatan Kemampuan Siswa dalam Memanfaatkan Citra Penginderaan Jauh dengan Menggunakan Google Earth Pada Matapelajaran Geografi di Kelas XII Madrasah Aliyah Negeri Surabaya. Jurnal Mahasiswa Teknologi Pendidikan (JMTP): Vol. 1, No. 1, 30 Januari 2011.

Shofiyati, Rizatus dan Wahyu Supriatna. 2011. Pemanfaatan Data Unduhan Gratis Dari Internet untuk Penelitian Sumberdaya Lahan. Jurnal Informatikan Pertanian, Vol 20 No.1, Agustus 2011, Hal 1-13.

Subaryono dan Djawahir. 2004. Pengantar Geodesi Geomatika. Bahan Ajar. Universitas Gadjah Mada.

Sukwardjono dan Mas Sukoco. 1997. Kartografi Dasar. Bahan Ajar. Universitas Gadjah Mada. Sutanto.1992. Penginderaan Jauh. Yogyakarta : Gadjah Mada University Press.

Trisakti, Bambang. 2012. Pemanfaatan Data Citra Satelit dalam Mendukung 
Pengelolaan SDA. Makalah. Optimalisasi Pemanfaatan Sistem Informasi Geografi dalam Perencanaan Ruang Konservasi-2012 Bogor.

Yousman, Yeyep. 2008. Google Earth. Yogyakarta: ANDI.

Yuanita, A., Andri Suprayogi dan Hania'ah. 2013. Kajian
Ketelitian Pemanfaatan Citra Quickbird PAda Google Earth untuk Pemetaan Bidang Tanah (Studi Kasus Kabupaten Karanganyar. Jurnal Geodesi Undip: Vol.2, No. 2, Hal. 3853. 